\title{
Antero mediastinal retrosternal goiter: surgical excision by combined cervical and hybrid robot-assisted approach
}

\author{
Dario Amore, Marcellino Cicalese, Roberto Scaramuzzi, Davide Di Natale, Carlo Curcio \\ Division of Thoracic Surgery, Monaldi Hospital, Naples, Italy \\ Correspondence to: Dario Amore. Division of Thoracic Surgery, Monaldi Hospital, Leonardo Bianchi Street, 1, 80131 Naples, Italy. \\ Email: dario.amore@alice.it
}

\begin{abstract}
Most intrathoracic goiters are located in the anterior mediastinum. Surgical resection is usually recommended in case of morbidity associated with the goiter's mass effect or for suspicion of malignancy difficult to diagnose without resection. Intrathoracic goiters are usually resected through a cervical approach, with sternotomy needed in selected cases. We report a case of antero mediastinal retrosternal goiter in old age patient undergoing surgical excision by combined cervical and hybrid robot-assisted approach. All steps of the thoracic procedure were completely performed using the da Vinci robot system with final extension of a port-site incision to extract the specimen. This approach provides more advantages than sternotomy regarding post operative clinical benefits and allows a more accurate surgical resection in the antero-superior mediastinum than conventional thoracoscopy.
\end{abstract}

Keywords: Goiter; mediastinum; robotic thoracic surgery

Submitted Nov 11, 2017. Accepted for publication Jan 23, 2018.

doi: $10.21037 /$ jtd.2018.01.169

View this article at: http://dx.doi.org/10.21037/jtd.2018.01.169

\section{Introduction}

Most intrathoracic goiters are found in the superior and anterior mediastinum (1). They are usually resected through a cervical incision but in selected cases a median sternotomy or a thoracotomy is indicated $(1,2)$. We report a case of intrathoracic goiter of the anterior mediastinum in old age patient undergoing surgical excision by combined cervical and hybrid robot-assisted approach with da Vinci robot system: all steps of the thoracic procedure were performed using minimally invasive technique with final extension of a port-site incision to extract the specimen by an endobag.

\section{Case presentation}

A 74-year-old woman, with history of dyspnea and image of widened mediastinum on chest X-ray, was referred to our hospital. Cervical-thoracic computed tomography scan revealed an encapsulated, heterogeneous mass of the anterior mediastinum arising from the left lower pole of thyroid gland. The mass, measuring $40 \mathrm{~mm} \times 40 \mathrm{~mm} \times$
$80 \mathrm{~mm}$, showed extension to the aortic arch (Figure 1). For surgical excision we performed a left thyroid lobectomy using a cervical approach. We decided to preserve the patient's right thyroid lobe because substernal thyroidectomy, as compared with conventional cervical thyroidectomy, is associated with an increased likelihood of recurrent laryngeal nerve injury. A careful traction of the mass and a blunt digital dissection failed to exteriorize the lesion in the neck due to adhesions to the surrounding mediastinal tissue. The mediastinal portion of the mass was then resected via a minimally invasive surgical technique using the da Vinci robot system for all steps of the procedure (Figure $2 A$ ). With patient already positioned supine on the operating table, the left hemithorax was elevated by a roll placed from the patient's hip to the level of the tip of scapula. Using three-port access, with $\mathrm{CO}_{2}$ insufflation into the pleural cavity, the mediastinal part of the goiter was completely dissected. The mass was then delivered transcervically down into the anterior mediastinum and removed by an endobag with final extension of a port-site incision. A 20-Fr chest tube was left in place with closure of cervical and thoracic incisions (Figure 2B). The microscopic 

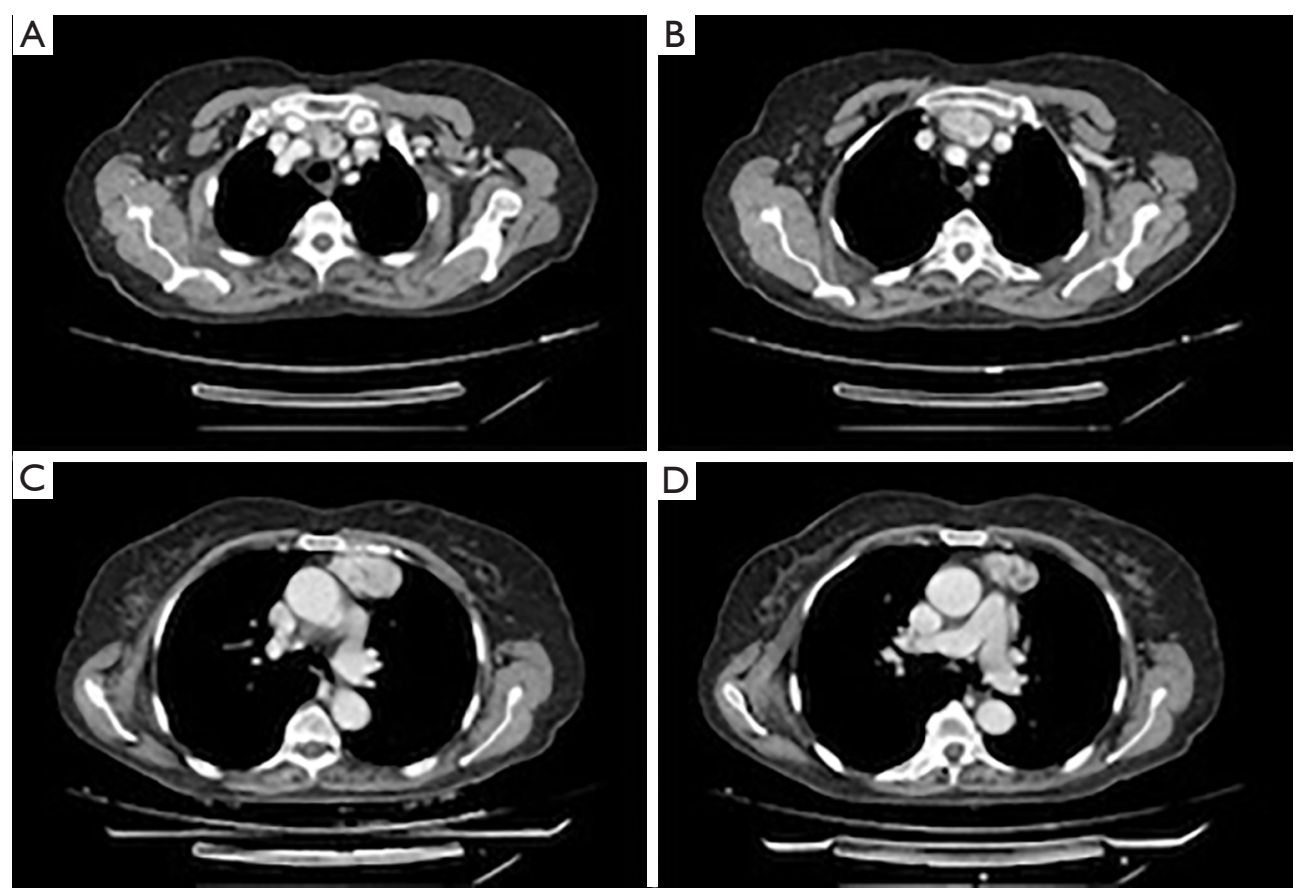

Figure 1 Contrast-enhanced computed tomography scan shows a sharply marginated, encapsulated mass in the anterior mediastinum arising from the thyroid gland.
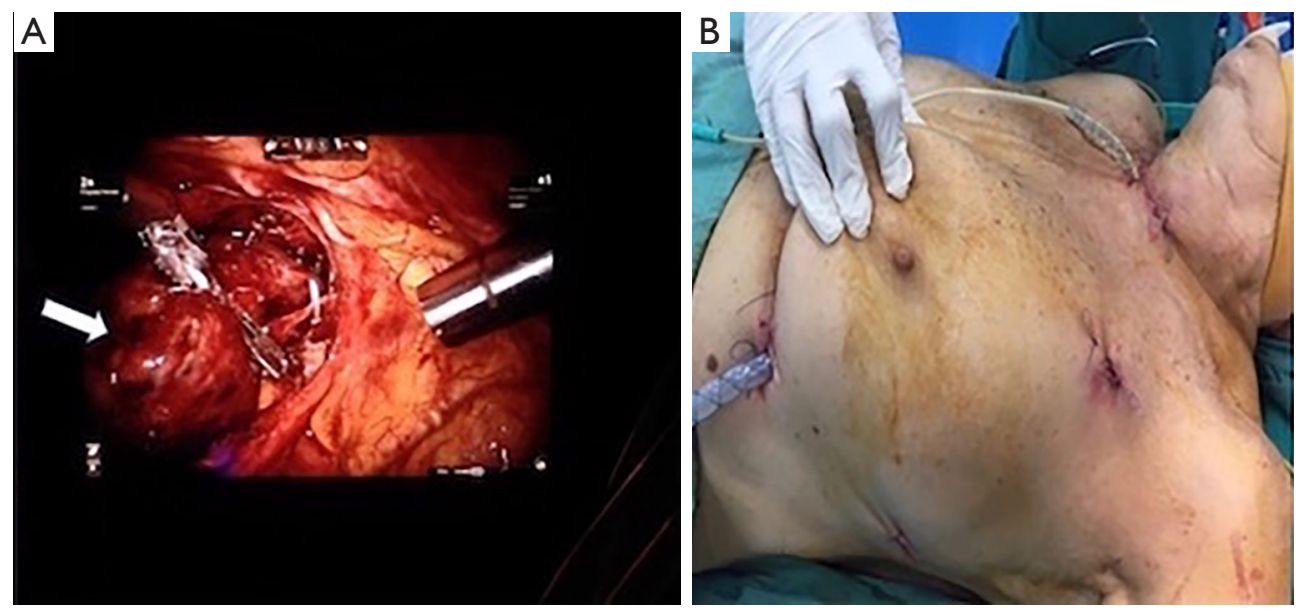

Figure 2 Delicate maneuvers of dissection in the anterior superior mediastinum performed via tiny thoracic incisions. (A) Cervical and thoracic incisions; (B) mediastinal portion of the mass (arrow) resected using the da Vinci robot system.

examination confirmed non-toxic multinodular goiter.

\section{Discussion}

Anterior goiters represent the $80 \%$ to $90 \%$ of intrathoracic goiters and usually extend to the left as soon as they descend through the thoracic inlet (3). Common presenting symptoms are: dyspnea, dysphagia, hoarseness, cough and syncope episodes (4). The chest X-ray usually shows the classic image of widened mediastinum with tracheal deviation but it's non specific . Computed tomography scan represents the best imaging modality with a sensitivity of 


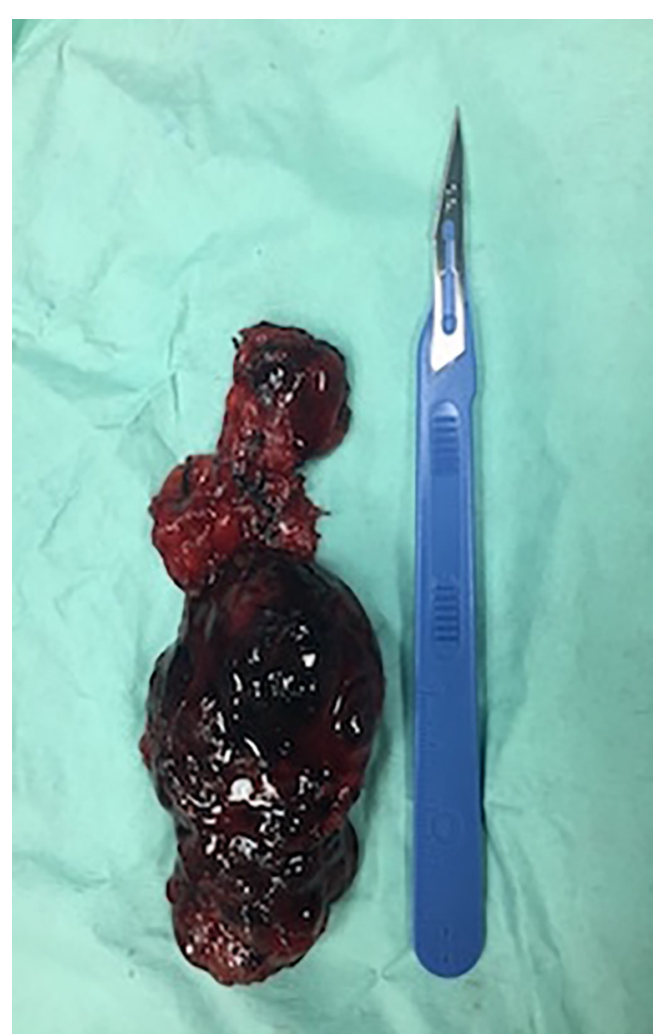

Figure 3 Surgical specimen consisting of left thyroid lobe and mediastinal portion of the mass.

$100 \%$ (5). Fine-needle aspiration cytology isn't advisable for intrathoracic goiters because they may conceal malignant cells that are likely to be missed (6). The treatment of choice for the intrathoracic goiters is the surgical resection because there is no good response to medical therapy in reducing their size (7) and because other treatments aren't able to improve symptoms due to mass effect of the goiter (8). The antero mediastinal intrathoracic goiters are usually resected through a cervical incision. In some cases, such as extension to aortic arch, presence of a retrosternal goiter with $>70 \%$ of the mass extending in the mediastinum, sternotomy or sternal split are required $(9,10)$. In our case we performed a surgical excision by combined cervical and hybrid robot-assisted approach using the da Vinci robot system to mobilize and dissect the antero mediastinal portion of the goiter that extended to the aortic arch with adhesions to the surrounding mediastinal tissue. Despite the fact that post operative morbidity is more common in patients undergoing retrosternal goiter resection than those undergoing thyroidectomy for cervical thyroid disease (11), in our case the patient had an uneventful post operative stay without a significant post operative morbidity such as dysphonia or deglutition problems and was discharged on the fifth post operative day. Hybrid robot-assisted surgical technique, for excision of the retrosternal goiter with antero mediastinal extension, in combination with cervical approach turned out to be safe and effective. The robotic approach allows lower intraoperative blood loss and lower perioperative complications than transsternal approach (12). Compared with sternotomy, it also presents other advantages: shorter tube days and faster return to routine activities (13). The robotic approach also provides more advantages than the conventional thoracoscopy: more precision dissection around vascular and nervous structure, better vision of the operative field with less risk of incomplete resection and 3-dimensional high vision $(14,15)$ These characteristics allow a more accurate surgical resection than conventional thoracoscopy that is challenged by the narrow anatomical structure of the antero-superior mediastinum due to limited movement of instruments (16). To our knowledge this is the first case reported in literature of antero mediastinal thyroid goiter undergoing surgical excision by combined cervical and hybrid robotassisted approach in which thoracic procedure, performed completely under endoscopic guidance, is then followed by final extension of a port-site incision to extract the specimen (Figure 3).

\section{Acknowledgements}

None.

\section{Footnote}

Conflicts of Interest: The authors have no conflicts of interest to declare.

Informed Consent: Written informed consent was obtained from the patient for publication of this case report and any accompanying images.

\section{References}

1. Podgaetz E, Gharagozloo F, Najam F, et al. A novel robotassisted technique for excision of a posterior mediastinal thyroid goiter: a combinated cervico-mediastinal approach. Innovations (Phila) 2009;4:225-8.

2. Nistor C, Ciuche A, Motaş C, et al. Cervico-mediastinal 
thyroid masses - our experience. Chirurgia (Bucur) 2014;109:34-43.

3. Buckley JA, Stark P. Intrathoracic mediastinal thyroid goiter: imaging manifestations. AJR Am J Roentgenol 1999;173:471-5.

4. Maruotti RA, Zannini P, Viani MP, et al. Surgical treatment of substernal goiters. Int Surg 1991;76:12-7.

5. Michel LA, Bradpiece HA. Surgical management of substernal goiter. Br J Surg 1988;75:565-9.

6. Madjar S, Weissberg D. Retrosternal goiter. Chest 1995;108:78-82.

7. Katlic MR, Wang CA, Grillo HC. Substernal goiter. Ann Thorac Surg 1985;39:391-9.

8. Shai SE, Chen CY, Hsu CP, et al. Surgical management of substernal goiter. J Formos Med Assoc 2000;99:827-32.

9. Batori M, Chatelou E, Straniero A. Surgical treatment of retrosternal goiter. Eur Rev Med Pharmacol Sci 2007;11:265-8.

10. Hedayati N, McHenry CR. The clinical presentation and operative management of nodular and diffuse substernal thyroid disease. Am Surg 2002;68:245-51.

11. Abboud B, Sleilaty G, Mallak N, et al. Morbidity and

Cite this article as: Amore D, Cicalese M, Scaramuzzi R, Di Natale D, Curcio C. Antero mediastinal retrosternal goiter: surgical excision by combined cervical and hybrid robot-assisted approach. J Thorac Dis 2018;10(3):E199-E202. doi: 10.21037/ jtd.2018.01.169 mortality of thyroidectomy for substernal goiter. Head Neck 2010;32:744-9.

12. Seong YW, Kang CH, Choi JW, et al. Early clinical outcomes of robot-assisted surgery for anterior mediastinal mass: its superiority over a conventional sternotomy approach evaluated by propensity score matching. Eur J Cardiothorac Surg 2014;45:e68-73.

13. Rea F, Marulli G, Bortolotti L. Robotic video-assisted thoracoscopic thymectomy. Multimed Man Cardiothorac Surg 2005;2005:mmcts.2004.000422.

14. Nakamura H, Taniguchi Y. Robot-assisted thoracoscopic surgery: current status and prospects. Gen Thorac Cardiovasc Surg 2013;61:127-32.

15. Ye B, Tantai JC, Li W, et al. Video-assisted thoracoscopic surgery versus robotic-assisted thoracoscopic surgery in the surgical treatment of Masaoka stage I thymoma. World J Surg Oncol 2013;11:157.

16. Kajiwara N, Kakihana M, Kawate N, et al. Appropriate set-up of the da Vinci Surgical System in relation to the location of anterior and middle mediastinal tumors. Interact Cardiovasc Thorac Surg 2011;12:112-6. 